\title{
絭 \\ An investigation of the behaviour of double oxide film defects in aluminium- magnesium cast alloys
}

\author{
by M.A. El-Sayed
}

\section{Synopsis}

Double oxide films (bifilms) are significant defects in light alloy castings that occur when, during melt handling, the oxidized surface of the melt is folded over onto itself and then entrained into the liquid metal, encapsulating a portion of the local atmosphere. These defects create crevices in the final castings and have been shown to decrease tensile and fatigue properties, and also to increase their scatter, making casting properties unreproducible and unreliable. This paper reports on two different experiments performed to study the behaviour of such defects in $\mathrm{Al}$ alloys. In the first experiment and as a proxy for a bifilm, air bubbles were held in an Al-5Mg alloy melt for varying periods of time before the melt was allowed to solidify. The composition of the gas content of the bubbles was subsequently analysed using mass spectrometry to ascertain how it changed with time. In the other experiment the influence of the age of bifilms on the mechanical properties of $\mathrm{Al}-5 \mathrm{Mg}$ castings was assessed by holding castings in the liquid state for different times before solidification, followed by mechanical property testing and SEM and EDX studies of the fracture surfaces of tensile test bars. This research could provide a better understanding of the behaviour of double oxide film defects, and may lead to the development of new techniques by which these defects could be eliminated, or at least deactivated, in light alloy castings.

Keywords

aluminium alloys, oxide films, entrainment, mechanical properties.

$$
M+O \rightleftarrows M O
$$

This reaction is reversible, and the direction that it takes depends upon the concentration of oxygen. When the oxygen concentration (or pressure) exceeds a certain value, the direction is to the right, with free metal and oxygen combining to form the oxide, and to the left at lower oxygen concentrations (Pilling and Bedsworth, 1923). Impey, Stephenson, and Nicholls (1990) studied the oxidation kinetics of pure aluminium and $\mathrm{Al}$ alloys with $\mathrm{Mg}$ contents of up to $5 \%$ in dry air at $750^{\circ} \mathrm{C}$. They reported that the addition of magnesium (from 1$5 \mathrm{wt} \%$ ) increased the rate of oxidation of the aluminium alloy. The authors suggested that for magnesium contents above $1.5 \mathrm{wt} \%$, the most stable oxide is $\mathrm{MgO}$, since it is in equilibrium with the lowest oxygen pressure. For magnesium contents in the range 0.02-1.5 $\mathrm{wt} \%$, the most stable oxide is $\mathrm{MgAl}_{2} \mathrm{O}_{4}$, and below this range, $\mathrm{Al}_{2} \mathrm{O}_{3}$.

$\mathrm{A}$ bifilm has no bonding between its inner faces and typically would form a crack in the solidified casting. Such cracks could be opened further during solidification, either under the negative pressure arising from the contraction of the solidifying metal or by the diffusion of hydrogen to fill the gap between the two layers of the bifilm, which has been held responsible for the formation of hydrogen porosity in $\mathrm{Al}$ casting (El-Sayed, Hassanin, and Essa, 2016). Submerged oxide films were also recognized as acting as nucleation sites for Fe-rich intermetallics (Campbell, 2006; El-Sayed and Griffiths, 2014). Therefore, the presence of this defect was reported to increase the scatter of the tensile and fatigue properties of the castings produced (Basuny et al., 2016).

* Department of Industrial and Management Engineering, Arab Academy for Science and Technology and Maritime Transport, Egypt.

(c) The Southern African Institute of Mining and Metallurgy, 2018. ISSN 2225-6253. Paper received Nov. 2017; revised paper received Jul. 2018. 


\section{An investigation of the behaviour of double oxide film defects in aluminium-magnesium}

It was suggested in a previous investigation (Nyahumwa, Green, and Campbell, 1998) that in pure Al melts, the transformation of the alumina constituting the bifilm from $\gamma$ alumina to $\alpha$-alumina would take about 5 hours. The associated volume change might initiate cracks in the film, forming a pathway by which the liquid aluminium can come into contact with, and react with, the gas inside the oxide film defect. This could result in the consumption of the atmosphere inside the bifilm and possibly contribute to its deactivation, which may minimize the detrimental effect on the mechanical properties of the castings.

Raiszadeh and Griffiths (2006) carried out an experiment in which a bubble of air, acting as an analogue for a double oxide film defect, was held in a melt of commercial purity Al for several hours, and real-time X-ray radiography was used to monitor the change in the bubble volume with time. Their results showed that the oxygen in the trapped air should be initially consumed to form $\mathrm{Al}_{2} \mathrm{O}_{3}$, then the nitrogen would react to form AlN. These reactions, as suggested, occurred as the skin of the air bubble was ruptured and resealed, rather than by diffusion of the interior gases through the oxide skin of the bubble. In addition, hydrogen dissolved in the melt might pass into the air bubble, increasing its volume, which supported the idea that double oxide film defects could play a role in the initiation of hydrogen porosity in Al cast alloys.

It should be noted that the amount of $\mathrm{Mg}$ in the $\mathrm{Al}$ alloy has a considerable effect on the type of the oxide formed. Silva and Talbot (1989) reported that at $725^{\circ} \mathrm{C}$ for an $\mathrm{Al}$ melt containing above $1.5 \mathrm{wt} \%$ magnesium, the most stable oxide is $\mathrm{MgO}$, whereas in $\mathrm{Al}$ alloys with $\mathrm{Mg}$ contents in the range $0.02-1.5 \mathrm{wt} \%$ the most stable oxide is $\mathrm{MgAl}_{2} \mathrm{O}_{4}$. Below $0.02 \mathrm{wt} \% \mathrm{Mg}$, alumina is expected to form. The oxygen and nitrogen reactions with the surrounding melt for different $\mathrm{Al}$ alloys are described by the following four equations eactions (Raiszadeh and Griffiths, 2006; Aryafar, Raiszadeh, and Shalbafzadeh, 2010; Yang et al., 1996; Griffiths, El-Sayed, and El-Sayed, 2016):

$$
\begin{aligned}
& 4 \mathrm{Al}+3 \mathrm{O}_{2} \rightarrow 2 \mathrm{Al}_{2} \mathrm{O}_{3} \\
& 2 \mathrm{Al}_{2} \mathrm{O}_{3}+2 \mathrm{MgO} \rightarrow 2 \mathrm{MgAl}_{2} \mathrm{O}_{4} \\
& 2 \mathrm{Mg}+\mathrm{O}_{2} \rightarrow 2 \mathrm{MgO} \\
& 2 \mathrm{Al}+\mathrm{N}_{2} \rightarrow 2 \mathrm{AlN}
\end{aligned}
$$

During casting of aluminium alloys, hydrogen is formed by the reaction of the melt with water vapour (Talbot, 1975). It is believed that hydrogen is the only gas that is soluble in aluminium and its alloys (Davis, 1993). Hydrogen molecules dissociate into the monatomic form and then are transported into the bulk liquid by diffusion. The ambient atmosphere is the main source of water vapour. However, fluxes, crucibles, refractories, and charge materials can also contain some moisture which can add hydrogen to the melt (El-Sayed, Shyha, and Basuny, 2018; El-Sayed, 2018.

The aim of this work was to study the change in the gas content with time of a bifilm defect held in an Al-5Mg alloy melt for different periods before solidification, and the corresponding influence on the mechanical properties of the castings. The consumption rates of the gases inside air bubbles held in a liquid $\mathrm{Al}$ alloy were studied, using mass spectroscopy, as an analogy for the behaviour of double oxide film defects. The reaction rates of oxygen and nitrogen in the bubble with the adjacent liquid metal, and the rate of hydrogen diffusion from the melt into the bubbles, were measured. Moreover, the tensile properties of castings comprising oxide films of different ages were evaluated and the fracture surfaces on tensile test bars were characterized using SEM and EDX analysis. The main objective of this study was to learn whether oxide film defects could be eliminated, or at least their deleterious effects reduced.

\section{Experimental work}

In order to characterize the development in the composition of an air bubble with time, as an analogue for a bifilm, a bubble was trapped inside an $\mathrm{Al}-5 \mathrm{Mg}$ alloy melt by submerging a steel bar containing a blind hole $6 \mathrm{~mm}$ in diameter and $5 \mathrm{~mm}$ in depth into the liquid metal. The steel bar was connected to a stirrer and was rotated at $540 \mathrm{r} / \mathrm{min}$ (equivalent to $1.4 \mathrm{~m} / \mathrm{s}$ at the position of the hole). The steel bar was left within the melt, subjected to stirring, for various periods ranging from 2 to 24 minutes. This would allow the air inside the hole in the bar to be in direct contact with the Al melt, enabling the air to react with the adjacent melt and hydrogen dissolved in the liquid metal to pass into the bubble. More details about the experimental procedure are described elsewhere (Griffiths, Caden, and El-Sayed, 2014, 2013; El-Sayed et al., 2013).

After the completion of the given holding time, the stirring was paused and the melt rapidly solidified (in approximately 30 seconds), trapping the air bubble with its contents. Afterwards, a cubic sample with an edge length of $15 \mathrm{~mm}$ was machined out of the solidified casting comprising the bubble trapped inside the hole in the steel bar. The gaseous content of the bubble was subsequently analysed using a pore gas analyser (PGA), (constructed by Hyden Ltd., Warrington, UK) containing a mass spectrometer, to measure the quantities of $\mathrm{H}, \mathrm{O}, \mathrm{N}$, and Ar in the bubble. After the gas in the bubble had been analysed, the surface of the solidified sample from the bubble's interior was removed and examined using SEM in order to verify the existence of different reaction products on the surface of the solidified $\mathrm{Al}$ alloy entrapped within the hole in the steel rod.

A reference air bubble, containing ambient atmosphere, was formed by sealing the bottom of a blind hole made from a $\mathrm{Cu}$ tube of the same dimensions. It was analysed in the pore gas analyser in order to determine the preciseness of this technique. A comparison of the results from the reference bubble with the nominal percentages of different gases in the ambient atmosphere suggested a variability in the results of the PGA of less than $2 \%$.

Another set of experiments was performed to assess the influence of the time spent by the Al melt in the liquid state before solidification, during which the interior atmosphere of the entrained bifilms was allowed to react with the surrounding melt and hydrogen dissolved in the melt could be diffused into the bifilms, on the mechanical properties of the castings produced. In these experiments, an investment casting technique was employed to produce $\mathrm{Al}-5 \mathrm{Mg}$ alloy castings that contained oxide films with different nominal ages; 0, 10 and 20 minutes. Three experiments were carried out in each about $10 \mathrm{~kg}$ of the alloy was melted and held at a 


\section{An investigation of the behaviour of double oxide film defects in aluminium-magnesium}

temperature of about $1073 \mathrm{~K}\left(800^{\circ} \mathrm{C}\right)$, under a vacuum of about $8 \mathrm{kPa}$ for 60 minutes. Such a process was anticipated to eliminate most of bifilms from the melt (Raiszadeh and Griffiths, 2010).

After the holding period under vacuum, the surface oxide layer was removed and the melt was poured from a height of about $1 \mathrm{~m}$ into preheated investment shell moulds. The surface turbulence associated with pouring from such a height was enough to cause entrainment of the oxidized surface of the melt during filling and hence introduce fresh bifilms into the melt. More details about the experimental setup can be found elsewhere (El-Sayed et al., 2011).

After pouring, one mould was left to freeze directly, while the two others were placed in a resistance-heated furnace at a temperature of about $800^{\circ} \mathrm{C}(1073 \mathrm{~K})$ to prevent solidification. These moulds were subsequently removed after different holding periods of 10 and 20 minutes, and allowed to solidify. The hydrogen content of the melt was evaluated during holding, using a Severn Science Hyscan H-measuring device.

Fifteen tensile test bars were obtained from each mould and tested using a Zwick 1484 tensile testing machine (Zwick GmbH \& Co. KG, Ulm, Germany) at a strain rate of $1 \mathrm{~mm}$ min-1. Tensile results were evaluated using a Weibull statistical analysis approach to assess the influence of the holding treatment on the mechanical properties of the castings. The fracture surfaces of the failed test bars were examined using a scanning electron microscope (SEM) fitted with an Oxford Inca energy-dispersive X-ray (EDX) analyser for microanalysis, which was used to confirm the presence of oxide film defects on the fracture surfaces.

\section{Results and discussion}

Experiments were carried out to investigate the influence of holding an Al-5Mg alloy melt in the liquid state for a given time before solidification on the behaviour of its entrained bifilm defects. As a proxy for a bifilm defect, an air bubble was trapped in liquid $\mathrm{Al}-5 \mathrm{Mg}$ alloy for various periods of time and subjected to stirring, and the change the gaseous content was studied. These results can be interpreted to help understand the change in the composition of the atmosphere of a bifilm defect floating within an Al melt. Additionally, the change in the morphology of the bifilms with time, and the corresponding impact on the mechanical properties of the castings, were investigated in detail.

\section{Change in gas composition of the bubbles}

Figure 1 shows a typical output from the pore gas analyser, presenting the results of analysis of the gas composition in an air bubble that had been held for 2 minutes and subjected to stirring at $540 \mathrm{r} / \mathrm{min}$ (1.4 $\mathrm{m} \mathrm{s}^{-1}$ angular velocity) inside an $\mathrm{Al}-5 \mathrm{Mg}$ alloy melt. The largest peak was associated with nitrogen, as anticipated, followed by oxygen, hydrogen, and argon, with traces of water vapour.

Figure 2a shows the change in the gaseous content with time for an air bubble kept inside an Al-5Mg alloy melt at $993 \mathrm{~K}\left(720^{\circ} \mathrm{C}\right)$ and subjected to stirring. The corresponding change in the volume of the bubble with time is shown in Figure $2 \mathrm{~b}$. As shown in Figure 2a, most of the oxygen content in the air bubble was lost within the first four minutes of holding, at a rate of about $9 \times 10^{-8} \mathrm{~mol} \mathrm{~min}^{-1}$.
There was an accompanying slower consumption of nitrogen at a rate of $5.7 \times 10^{-8} \mathrm{~mol} \mathrm{~min}^{-1}$, and a further slower diffusion of hydrogen into the bubble at an approximate rate of $2.8 \times 10^{-8} \mathrm{~mol} \mathrm{~min}^{-1}$. There was a noticeable increase in the rate of hydrogen diffusion into the bubble after the oxygen inside the bubble had been consumed (which took about 4 minutes). After 24 minutes' holding, the composition of the bubble principally comprised nitrogen and hydrogen. At this time, the bubble had reached about $46 \%$ of its initial volume (Figure $2 \mathrm{~b}$ ).

Nyahumwa, Green, and Campbell (1998) and Raiszadeh and Griffiths (2006) suggested that the internal atmosphere of oxygen and nitrogen in a bifilm could be consumed by reaction with the adjoining molten metal. By the same token, soluble hydrogen in the melt may diffuse into the bifilm gap (Griffiths and Raiszadeh, 2009). As the Gibbs free energies

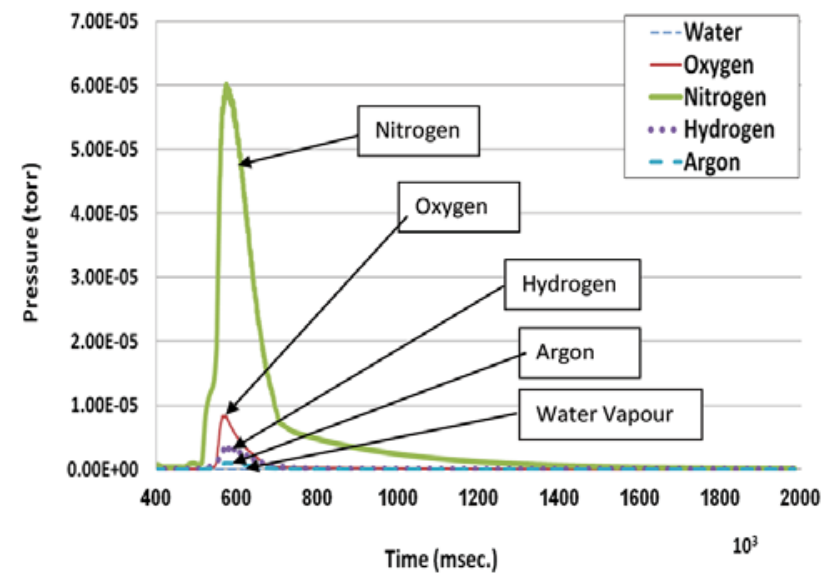

Figure 1-An example of the output from the pore gas analyser

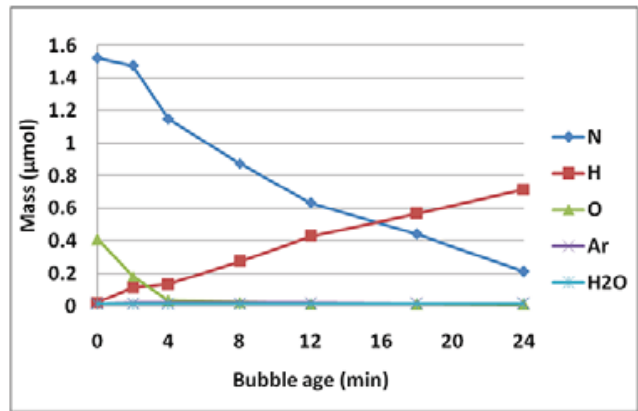

(a)

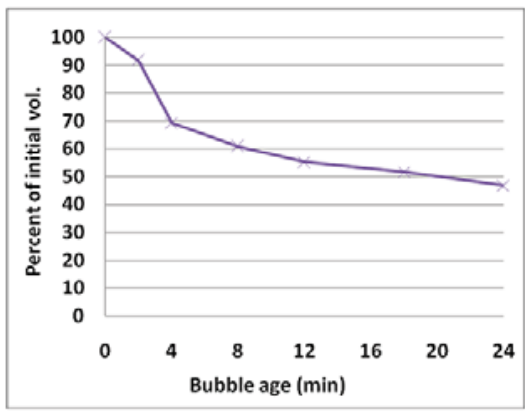

(b)

Figure 2-(a) Changes in bubble composition with holding time in an Al$5 \mathrm{Mg}$ melt. (b) Changes in the volume of the air bubble with time 


\section{An investigation of the behaviour of double oxide film defects in aluminium-magnesium}

of formation (for the reaction of one mole of $\mathrm{O}_{2}$ at $1000 \mathrm{~K}$ $\left(727^{\circ} \mathrm{C}\right)$ ) to form $\mathrm{MgO}$ and $\mathrm{Al}_{2} \mathrm{O}_{3}$, are -986 and $-940 \mathrm{~kJ} \mathrm{~mol}-1$ respectively, whereas that for AlN is $-423.6 \mathrm{~kJ} \mathrm{~mol}^{-1} \mathrm{~N}_{2}$ at $1000 \mathrm{~K}\left(727^{\circ} \mathrm{C}\right)$ (Chase, 1985; Brandes and Brook, 1999), the liquid alloy would first consume all of the oxygen in the atmosphere of a bifilm, producing $\mathrm{MgO}$, and then nitrogen might begin to react to form AlN. The Gibbs free energy for the reaction of one mole of $\mathrm{N}_{2}$ at $1000 \mathrm{~K}\left(727^{\circ} \mathrm{C}\right)$ to form $\mathrm{Mg}_{3} \mathrm{~N}_{2}$ is $0150206.61 \mathrm{~kJ} \mathrm{~mol}-1 \mathrm{~N}_{2}$ (Chase, 1985), indicating that for Al-5Mg alloy, AlN is the nitride more likely to form, rather than $\mathrm{Mg}_{3} \mathrm{~N}_{2}$.

In the current experiments, it was shown that both oxygen and nitrogen were consumed with time (with oxygen being consumed first). On the other hand, as the melt remained longer in the liquid state, the hydrogen content of the bubbles increased, which was in accordance with previous results (Raiszadeh and Griffiths, 2006; El-Sayed et al., 2013). Notably, as the oxygen content of the bubble atmosphere reached about $2 \%$, the nitrogen content of the bubble started to diminish. In other words, the beginning of nitrogen consumption was independent of the complete consumption of oxygen; this corroborates the work of Raiszadeh and Griffiths (2006), who hypothesised that nitrogen in a static air bubble held within an Al melt starts reacting with the surrounding liquid metal once the oxygen concentration in the bubble reaches around $5 \%$ by volume.

It should be also noted that no change was detected in the quantities of either argon or water vapour in bubbles of different ages, as shown in Figure $2 \mathrm{a}$, these values being constant at about $5.2 \times 10-8$ and $2.8 \times 10-8$ moles, representing about $1.3 \%$ and $0.7 \%$ respectively of the bubble volume. Therefore, only the changes in the amounts of nitrogen, oxygen, and hydrogen were considered in this study.

Figure 3a shows a SEM micrograph of the surface of a sample from inside a bubble that was held within an Al-5Mg melt for 24 minutes before solidification. EDX spectra at locations X1 and X2, presented in Figures 3b and 3c, indicated the existence of AlN and MgO respectively. This suggests that the oxygen and nitrogen within the trapped air bubble were consumed by reactions with the surrounding melt, producing MgO and AlN, respectively. The existence of such species on the sample surfaces was confirmed by the corresponding EDX spectra. The oxygen peak noticed at location X1 (Figure 3b) indicates the presence of an underlying MgO layer. This further confirms the suggestions that oxygen was consumed first to create a magnesia film, and nitrogen would have then seeped through the cracks in the film to react with the melt forming an AlN layer on the Mgo film.

According to Weigel and Fromm (1990), liquid aluminium is likely to be always covered with a layer of oxide because of its extreme reactivity. If broken, this layer is expected to re-form almost immediately. Any discontinuities in the oxide film could allow $\mathrm{O}_{2}$ from the atmosphere to diffuse across the film into the melt, allowing oxidation to continue (Sleppy, 1961).

The magnesia layer is expected to be porous and permeable, since the Pilling-Bedworth ratio ( $\mathrm{PBR}$ ) of $\mathrm{MgO}$ is about 0.84 (Pilling and Bedworth, 1923). Such permeability would create leakage paths for oxygen (and subsequently nitrogen) to flow outwards through the initially formed oxide

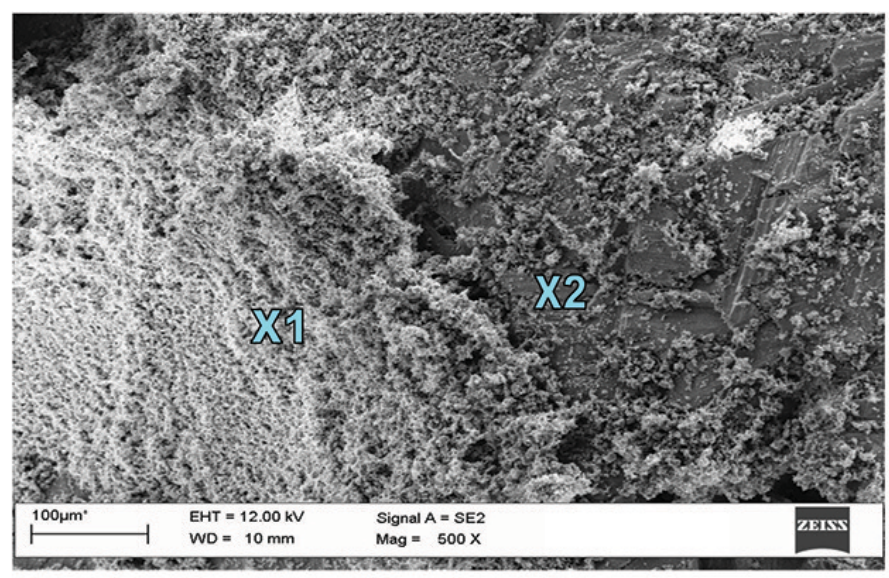

(a)
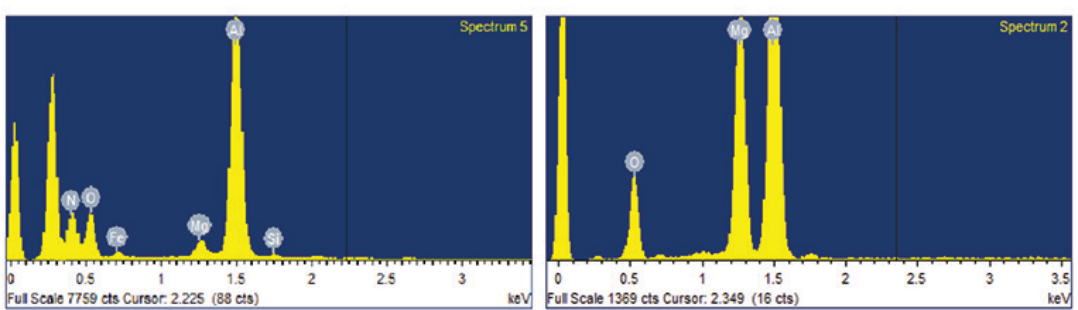

(b)

(c)

Figure 3-(a) SEM micrograph of the surface of a sample held in an Al-5Mg melt for 24 minutes; (b) and (c) EDX spectra at locations X1 and X2 in (a) respectively 


\section{An investigation of the behaviour of double oxide film defects in aluminium-magnesium}

layer and react with the adjacent melt, leading to the complete depletion of the former. Accordingly, most of the oxygen inside the air bubble was depleted in only about 4 minutes. The AlN layer, on the contrary, is anticipated to constitute a continuous protective layer with a PBR of 1.26 (Pilling and Bedworth, 1923). However, a significant pressure on the oxide and nitride layers (between the melt and the bubble) would be induced by the spinning action of the air bubble in the melt (which simulated the movement of a bifilm within a flowing liquid metal). This may lead to the tearing of the oxide and nitride layers. Such cracks would act as leakage paths, enabling the nitrogen (and remaining oxygen) to react with the molten metal.

\section{Evaluation of the mechanical properties of the castings}

As suggested in previous research to be more appropriate than a normal fit, the two-parameter Weibull distribution was used of in order to analyse the tensile properties of the Al$5 \mathrm{Mg}$ alloy castings (Green and Campbell, 1993). The slope of the line fitted to the log-log Weibull cumulative distribution data (known as the Weibull modulus) is indicative of the spread of properties; a higher Weibull modulus implies a narrower spread of properties.

Figures $4 \mathrm{a}$ and $4 \mathrm{~b}$ illustrate the Weibull plots of the UTS and percentage elongation, respectively, of the test bars cut from castings that were held in the furnace for 0,10 , and 20 minutes before solidification. The $\mathrm{R}^{2}$ values of approximately 0.95 show that these values were obtained from relationships that were a good linear fit to the data obtained (Tiryakioglu, Hudak, and Okten, 2009). The castings maintained at $1073 \mathrm{~K}$ $\left(800^{\circ} \mathrm{C}\right)$ for 10 minutes prior to cooling obviously experienced enhanced Weibull moduli of their UTS and percentage elongation, as indicated by the steeper slopes of the trend lines compared to the castings solidified immediately or held in the liquid state for 20 minutes before solidification.

Figure 5 a depicts plots of the Weibull moduli of both the UTS and the percentage elongation of the Al-5Mg alloy castings against the holding time before solidification. The Weibull modulus of the UTS has a value of 22 for samples allowed to solidify without holding, rising to 31 after holding for 10 minutes and dropping again to 24 after 20 minutes' holding. The percentage elongation data shows the same behaviour, with a Weibull modulus of 9.7 at zero minutes, 13.8 at 10 minutes, and 8.4 at 20 minutes.The moduli, in other words, were a maximum at 10 minutes' holding time prior to cooling. Figure $5 \mathrm{~b}$ depicts a plot of the amount of hydrogen in solution in the liquid metal versus holding time; a steady rise in the hydrogen content of the alloy with holding time is evident.

Figure 6a shows a SEM micrograph, with the corresponding EDX analysis, of an oxide layer found on the fracture surface of a specimen from the casting solidified immediately after pouring. Another SEM image of a pore on the fracture surface of a specimen from an $\mathrm{Al}-5 \mathrm{Mg}$ alloy casting that was held in the liquid state for 20 minutes prior to solidification is shown in Figure 6b, in which a number of oxide fragments were found located over the dendrites inside the pore. The EDX analyses suggest that the oxide layers are $\mathrm{MgO}$.

Almost all of the magnesia films found on the fracture surfaces (not inside the pores) of the test bars were associated with castings that had solidified immediately after pouring. Castings held in the liquid state for 10 or 20 minutes prior to cooling were devoid of any bifilms on the fracture surfaces of the test bars. Many MgO fragments, nevertheless, were detected inside pores on the fracture surfaces of these castings. This suggests that the holding treatment may modify the morphology of bifilms in Al castings and cause them to form pores. This could be indicative of the effect of the holding treatment on the removal of oxide films, or at least changing their morphologies to form hydrogen porosity in light metal alloy castings.
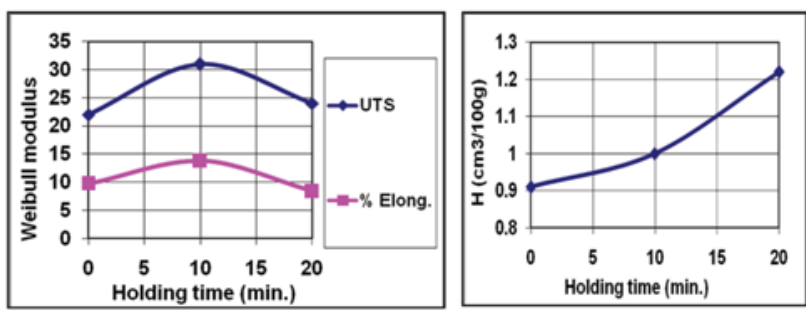

Figure 5-Plots of holding time versus (a) Weibull moduli of the UTS and percentage elongation, (b) hydrogen content of the melt

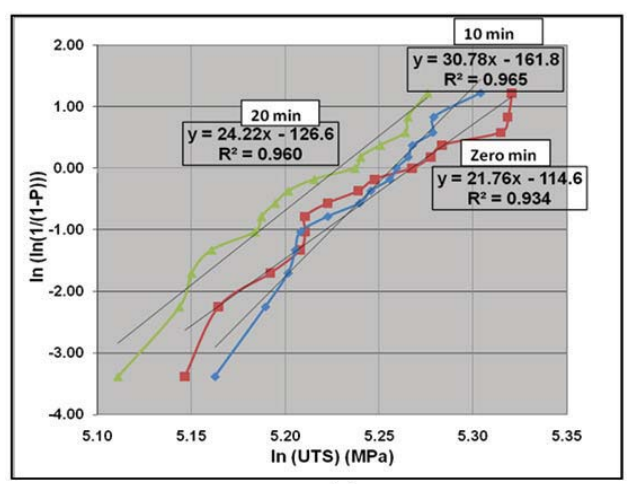

(a)

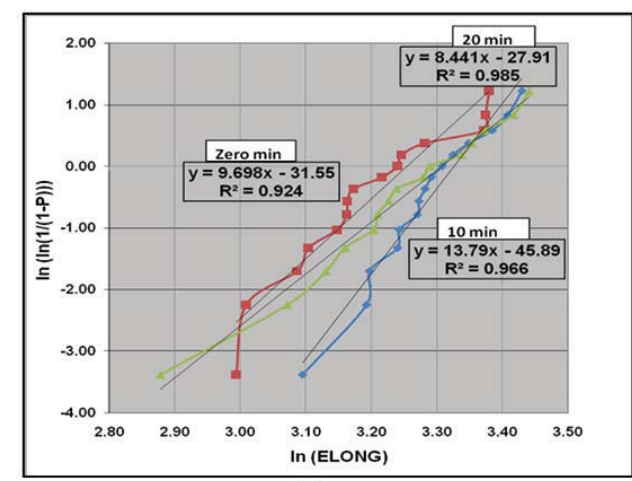

(b)

Figure 4-Weibull distributions of (a) the ultimate tensile strength and (b) the percentage elongation of Al-5Mg alloy specimens held in the liquid state for 0 , 10 , and 20 minutes before solidification 


\section{An investigation of the behaviour of double oxide film defects in aluminium-magnesium}
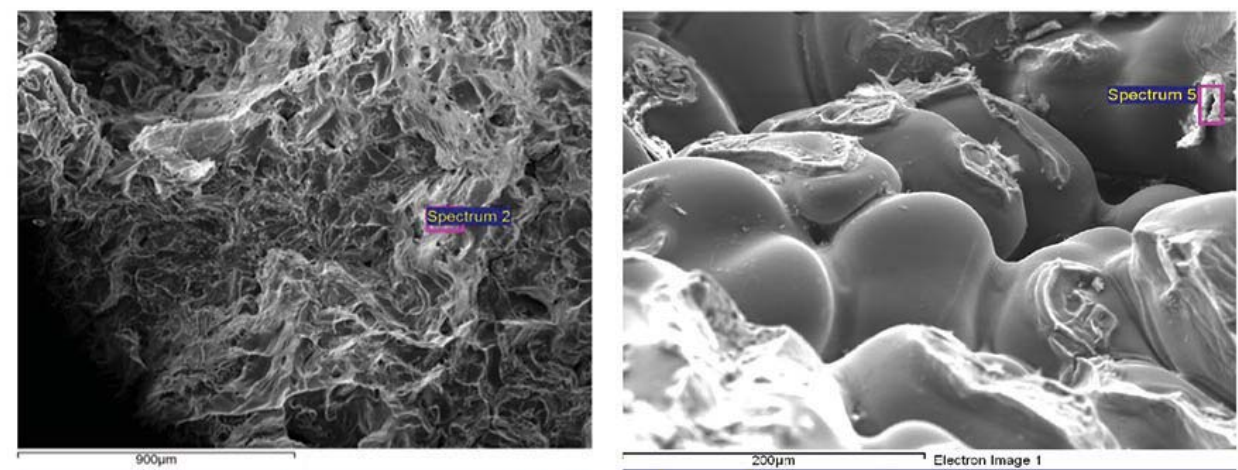

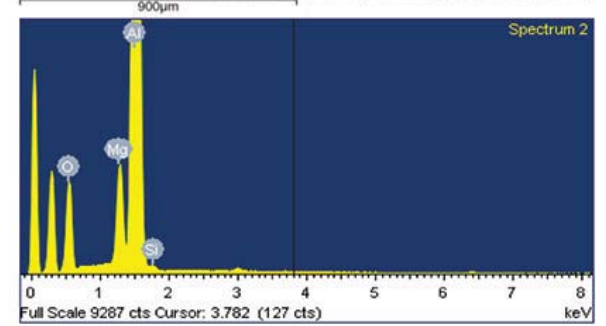

(a)

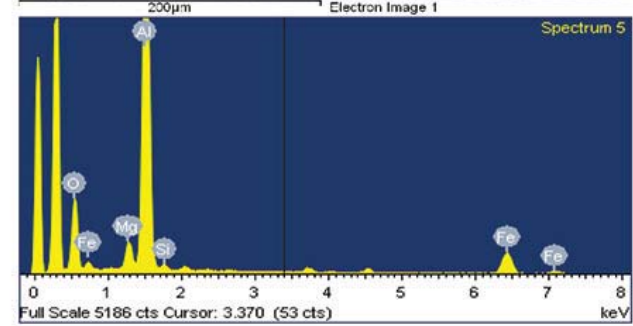

(b)

Figure 6-SEM images with corresponding EDX analyses of the fracture surfaces of Al-5Mg alloy specimens that contain oxide films of different ages, (a) zero minotes and (b) 20 minutes

Correlating the change in the composition of air bubbles with time with the change in the Weibull moduli of the castings, it could be suggested that oxygen was consumed initially from inside the bifilm defects, and then nitrogen as a result of reaction with the adjacent $\mathrm{Al}$ melt. This would decrease the size of bifilm defects and hence reduce their harmful effects on the mechanical properties of $\mathrm{Al}$ castings. Also, hydrogen would spread out into the bifilm, initially slowly (during the consumption of oxygen), but then at a faster rate during the consumption of nitrogen.

In the test bars solidified after pouring, the UTS and percentage elongation Weibull moduli were relatively low (22 and 9.7, respectively), perhaps due to the presence of many bifilm defects in the castings, as shown in Figure $6 \mathrm{a}$, which resulted in a reduction in the reproducibility of casting properties. Holding the castings in the liquid state for 10 minutes before solidification seems to cause a reduction of the internal atmosphere of the bifilms by reaction of oxygen (and subsequently nitrogen) with the surrounding melt. As the volume of the internal atmosphere decreased, the size of the defects, and their effect on mechanical properties, was correspondingly reduced, resulting in an increase in the Weibull moduli to values of about 31 and 13.8, respectively. With further holding up to 20 minutes, the double oxide film defects expanded because of the diffusion of hydrogen into their atmospheres, which increased the number and size of oxide-related hydrogen-contacting porosity on the fracture surfaces, as shown in Figure 6b, and correspondingly decreased the Weibull moduli to 24 and 8.4, respectively. This could be a confirmation of previous results (El-Sayed et al., 2011), which suggested that two contending mechanisms affect the size and morphology of the bifilms.

To sum up, the change in mechanical properties and the results of the analyses of air bubbles suggest that once formed, double oxide films quickly undergo changes in their internal atmosphere which change the size and shape of the films and thus their effect on mechanical properties. These changes are the rapid consumption of oxygen and a slower accumulation of hydrogen. Subsequent to the reaction of oxygen, nitrogen is consumed, which is also a slower process, although the complete consumption of oxygen does not seem to be required prior to the formation of AlN. The consumption of oxygen and nitrogen in the bifilm atmosphere causes a decrease in the size of the defects and enhances the properties of the casting, whereas the diffusion of hydrogen into the bifilms increases their size, resulting in an adverse effect on the properties.

\section{Conclusions}

1. The oxygen and nitrogen in an air bubble (which was considered as a proxy for a double oxide film defect) confined in an Al-5Mg alloy melt were consumed by reaction with the surrounding liquid metal to form $\mathrm{MgO}$ and AlN, respectively. This was confirmed by SEM and EDX analysis of the surfaces of samples obtained from inside the bubbles that indicated the existence of both species, with evidence that AlN might be nucleated on a previously-formed magnesia layer.

2. The longer the time a bubble (or a bifilm) is retained in the melt, the more hydrogen diffuses into it. This occurred most speedily at the moment when the bifilm's internal oxygen had been consumed.

3. Detection of magnesia films on almost all of the fracture surfaces of the test bars from different Al-5Mg alloy castings, irrespective of the holding time, suggested that the failure of Al castings is dominated by the presence of such defects. SEM examination of the fracture surfaces showed that porosity was often associated with oxide film defects. 


\section{An investigation of the behaviour of double oxide film defects in aluminium-magnesium}

4. Holding of an $\mathrm{Al}-5 \mathrm{Mg}$ alloy casting at $1073 \mathrm{~K}\left(800^{\circ} \mathrm{C}\right)$ for 10 minutes before solidification enhanced the Weibull moduli of the UTS and percentage elongation of the castings by approximately $41 \%$ and $42 \%$ respectively. This is suggested to be caused by the gaseous content of oxide film defects becoming exhausted, which decreases the size of the films and accordingly their influence on mechanical properties.

5. The amount of hydrogen diffused into bifilms is suggested to increase by extending the holding period to 20 minutes, perhaps resulting in the formation of oxide-related hydrogen-containing porosity. This caused a reduction in the Weibull moduli of the UTS and percentage elongation by about $23 \%$ and $39 \%$ respectively.

\section{Acknowledgements}

The author would like to thank of Mr. Adrian Caden of the University of Birmingham for his technical assistance. The author also gratefully acknowledges the excellent supervision, guidance, motivation, and sincere support of Dr Bill Griffiths of the University of Birmingham during the preparation of this work.

\section{References}

Aryafar, M., Raiszadeh, R., and Shalbafzadeh, A. 2010. Healing of double oxide film defects in A356 aluminium melt. Journal of Materials Science, vol. 45, no. 11. pp. 3041-3051.

Basuny, F.H., GHAZy, M.. KANDEIL, A.-R.Y., and El-SAyed, M.A. 2016. Effect of casting conditions on the fracture strength of Al-5 Mg alloy castings. Advances in Materials Science and Engineering, vol. 2016. doi:10.1155/2016/6496348

Brandes, E.A. and ВRоoк, G.B. 1999. Smithells Metals Reference Book. 7th edn. Butterworth-Heinemann, Oxford.

CAmpBelL, J. 2003. Castings. 2nd. edn. Butterworth-Heinemann.

CAmpBelL, J. 2006. Entrainment defects. Materials Science and Technology, vol. 22, no. 2. pp. 127-145. doi:10.1179/174328406x74248

CHASE, M.W. 1985. JANAF Thermochemical tables. Journal of Physical and Chemical Reference Data, vol. 14. American Chemical Society/American Institute of Physics for the National Bureau of Standards, Ann Arbor, Michigan.

DAvis, J.R. 1993. Aluminum and Aluminum Alloys. 1st edn. ASM Specialty Handbook. ASM International, Materials Park, Ohio:

EL-SAYED, M. and GHAZY, M. 2017. Entrained defects in light metal cast alloys Journal of the Southern African Institute of Mining and Metallurgy, vol. 117, no. 7. pp. 656-662.

EL-SAyed, M., HasSAnin, H., and EsSA, K. 2016. Effect of casting practice on the reliability of Al cast alloys. International Journal of Cast Metals Research, vol. 29, no. 6. pp. 350-354.

El-Sayed, M., SAlem, H.G., KAndeIl, A.-R., and Griffiths, W.D. 2013. A study of the behaviour of double oxide films in Al alloy melts. Materials Science Forum, vol. 765. pp. 260-265.

El-Sayed, M.A. 2016. The behaviour of bifilm defects in cast Al-7Si-Mg alloy. PloS One, vol. 11, no. 8. pp. e0160633.

EL-SAYED, M.A. 2018. Influence of mould design and hydrogen content on the tensile properties of Al-Mg cast alloys. Journal of Engineering Technology, vol. 6, no. 1. pp. 584-594.

EL-SAYed, M.A. and Essa, K. 2017. Effect of mould type and solidification time on bifilm defects and mechanical properties of $\mathrm{Al}-7 \mathrm{Si}-0.3 \mathrm{Mg}$ alloy castings. International Journal of Computational Methods and Experimental Measurements, vol. 6, no. 4. pp. 647-655.

EL-SAYED, M.A. and GRIFFITHS, W.D. 2014. Hydrogen, bifilms and mechanical properties of Al castings. International Journal of Cast Metals Research, vol. 27, no. 5. pp. 282-287. doi:10.1179/1743133614Y.0000000113

EL-SAYED, M.A., HASSAnin, H., and EsSa, K. 2016. Bifilm defects and porosity in Al cast alloys. International Journal of Advanced Manufacturing Technology, vol. 86, no. 5. pp. 1173-1179. doi:10.1007/s00170-0158240-6

El-SAYed, M.A., SAlem, H.A.G., KandeIl, A.Y., and GrifFiths, W.D. 2011. Effect of holding time before solidification on double-oxide film defects and mechanical properties of aluminum alloys. Metallurgical and Materials Transactions B: Process Metallurgy and Materials Processing Science, vol. 42, no. 6. pp. 1104-1109. doi:10.1007/s11663-011-9571-9

EL-SAYED, M.A., SHYHA, I., and BASUnY, F.H. 2018. Effect of hydrogen content on the double oxide film defects and properties of aluminium castings: A review. Journal of Engineering Technology, vol. 6. pp. 225-244.

GREEN, N.R. and CAMPBELL, J. 1993. Statistical distributions of fracture strengths of cast Al-7Si-Mg alloy. Materials Science and Engineering A, vol. 173, no.1-2. pp. 261-266. doi:10.1016/0921-5093(93)90226-5

Griffiths, W., CAdEn, A., And El-Sayed, M. 2013. The behaviour of entrainment defects in aluminium alloy castings. Proceedings of the 2013 International Symposium on Liquid Metal Processing \& Casting. Springer. doi:10.1002/9781118830857.ch28

Griffiths, W.D., CADEN, A., and El-SAyED, M. 2014. An investigation into double oxide film defects in aluminium alloys. Materials Science Forum, vol. 783-786. pp. 142-147.

GrifFithS, W.D., El-SAYED, A., and El-SAYED, M.A. 2016. Whisker formation in porosity in Al alloys. Metallurgical and Materials Transactions B, vol. 47, no. 6. pp. 3459-3468.

GRIFFITHS, W.D. and RAISZADEH, R. 2009. Hydrogen, porosity and oxide film defects in liquid Al. Journal of Materials Science, vol. 44, no. 13. pp. 3402-3407

IMPEY, S., STEPHENSON, D., and Nicholls, J.R. 1990. A study of the effect of magnesium additions on the oxide growth morphologies on liquid aluminium alloys. Proceedings of the International Conference on the Microscopy of Oxidation, Cambridge University. Institute of Metals.

Nyahumwa, C., GreEn, N.R., and CAmpbell, J. 1998. Effect of mold-filling turbulence on fatigue properties of cast aluminum alloys. AFS Transactions, vol. 106. pp. 215-223.

Pilling, N.B. and Bedsworth, R.E. 1923. The oxidation of metals at high temperatures. Journal of the Institute of Metals, vol. 29. pp. 529-591.

RAISZADEH, R. and GRIFFITHS, W.D. 2006. A method to study the history of a double oxide film defect in liquid aluminum alloys. Metallurgical and Materials Transactions B, vol. 37, no. 6. pp. 865-871.

RAISZADEH, R. and GrifFiths, W.D. 2010. The behaviour of double oxide film defects in liquid $\mathrm{Al}$ alloys under atmospheric and reduced pressures. Journal of Alloys and Compounds, vol. 491, no. 1-2. pp. 575-580. doi:10.1016/j.jallcom.2009.10.271

SILVA, M.P. and TALBOT, D.E.J. 1989. Oxidation of liquid aluminum-magnesium alloys. Proceedings of the 118th Annual Meeting. Las Vegas, Nevada. Technical Sessions, TMS Light Metals Committee.

SLEPPY, W.C. 1961. Oxidation of molten high-purity aluminum in dry oxygen Journal of the Electrochemical Society, vol. 108, no. 12. pp. 1097-1102.

TALBoT, D.E.J. 1975. Effects of hydrogen in aluminium, magnesium, copper, and their alloys. International Materials Reviews, vol. 20, no. pp. 166-184.

Tiryakioglu, M., НudAK, D., and ОктEN, G. 2009. On evaluating Weibull fits to mechanical testing data. Materials Science and Engineering A, vol. 527, no. 1-2. pp. 397-399.

Weigel, J. and Fromm, E. 1990. Determination of hydrogen absorption and desorption processes in aluminum melts by continuous hydrogen activity measurements. Metallurgical and Materials Transactions B, vol. 21, no. 5 . pp. 855-860. doi:10.1007/bf02657810

YAng, L., Zhu, D., Xu, C., Zhang, J., and Zhang, J. 1996. On the role of magnesium and silicon in the formation of alumina from aluminum alloys by means of DIMOX processing. Metallurgical and Materials Transactions A, vol. 27, no. 8. pp. 2094-2099. doi:10.1007/bf02651863 